\title{
Avaliação Formativa: ensaio de uma arqueologia
}

\author{
ZACARIAS JAEGGER GAMA \\ Doutor em Educação pela Universidade Federal do Rio de Janeiro - UFRJ \\ Professor Adjunto do Departamento de Estudos Aplicados ao Ensino da Faculdade \\ de Educação da Universidade do Estado do Rio de Janeiro - UERJ \\ Professor Titular do Programa de Pós-graduação do Instituto Superior \\ de Estudos Pedagógicos - Isep \\ jacgger@hotmail.com
}

\begin{abstract}
Resumo
Neste texto ensaia-se a elaboração de uma arqueologia do discurso da avaliação formativa, considerando-se os enunciados mais recorrentes no âmbito da escola pública do Estado do Rio de Janeiro. A intenção é dar visibilidade às unidades deste discurso em termos de continuidade entre suas irrupções, bem como examinar a existência de um discurso que seja o mesmo em qualquer acepção, e investigar a que tipos de leis obedecem e se correspondem de fato à avaliação formativa. Foram considerados os enunciados presentes no estruturalismo, nos sistemas cibernéticos e no tecnicismo. O esforço empreendido revela a dispersão existente e as possíveis opções de filiações metodológicas, recomendando-se que qualquer prática de avaliação formativa seja precedida de muita cautela e sejam aprofundadas reflexões, em função de seu tom conservador e da falta de alternativas ao desenvolvimento das teorias de currículo pós-críticas e de por em xeque o poder.

Palavras-chave: avaliação formativa, estruturalismo, sistemismo, tecnicismo.
\end{abstract}

\section{Resumen}

En este texto se intenta la elaboración de una arqueología del discurso de la evaluación formativa, teniendo en cuenta las premisas más recurridas en el ámbito de la escuela pública del Estado de Río de Janeiro. Trata de dar visibilidad a las unidades de este discurso desde el punto de vista de la continuidad; así como analizar la existencia de un mismo discurso independiente de cualquier acepción e investigar a que tipos de leyes obedecen y si corresponden de hecho a la evaluación formativa. Se consideraron las premisas existentes en el estructuralismo, en los sistemas cibernéticos y en el tecnicismo. El esfuerzo dispensado revela la dispersión existente y las posibles opciones de filiaciones metodológicas, recomendándose que la aplicación de cualquier forma de evaluación formativa sea precedida de muchos cuidados y profundas reflexiones en función de su tono conservador y de la falta de alternativas para el desarrollo de las teorías curriculares pos-críticas y de desafio del poder.

Palabras-clave: evaluación formativa, estructuralismo, sistemismo, tecnicismo. 


\begin{abstract}
In this essay, we intend to develop an archeology for the discourse of formative evaluation, considering the most recurrent utterances in public schools in the State of the Rio de Janeiro. We aim at highlighting the units of this discourse in terms of their continuity, and analyzing the existence of one discourse as being the same. At last we would like to investigate the types of laws they abide by and if they actually correspond to formative evaluation. We have considered the discourses of Structuralism, Cybernetics Systems and "Technicism". The results reveal the existing dispersion and the possible options, considering that the use of formative evaluation needs be preceded by great caution and serious reflections because of its conservative tone and of the lack of alternatives for the development of post-critical curriculum theories and of not questioning the aspect of power.
\end{abstract}

Key words: formative evaluation, structuralism, "Systemism”, "Technicism”. 


\section{INTRODUÇÃO}

A avaliação formativa como discurso tem sido recorrente no meio educacional brasileiro. As políticas educacionais, destacando-se em particular os Parâmetros Curriculares Nacionais e Exame Nacional do Ensino Médio (Enem), tendem claramente, desde a década passada, a incorporá-la às práticas avaliativas realizadas nas escolas públicas brasileiras. Diversos autores e estudiosos de avaliação, por sua vez, encarregam-se de sua veiculação procurando convencer acerca de sua vantagem. No Rio de Janeiro tem sido fácil encontrar unidades deste discurso entre vários professores de escolas públicas, uns afirmando já fazer uso de avaliações formativas em suas práticas escolares há bastante tempo; outros, ainda às voltas com a utilização prática.

Nos limites deste ensaio, cabe dar visibilidade às unidades deste discurso em termos de continuidade entre suas irrupções, bem como examinar a existência de um discurso que seja o mesmo em qualquer acepção e a que tipos de leis obedecem. Com este intuito, se toma aqui a teoria da avaliação formativa como discurso, entendendo que os discursos são produtores de noções particulares e de efeitos de realidade, isto é, nos levam a assumir posições e constróem na realidade aquilo que retoricamente descrevem. Também se procura compreender algumas questões específicas que caracterizam as unidades do discurso da avaliação formativa, em uma perspectiva foucaultiana ou pós-estruturalista, considerando o discurso da avaliação, qualquer que seja sua prática, como uma questão de poder. $\mathrm{O}$ discurso avaliativo, afinal, não é neutro ou desinteressado. Os simples "o quê" e "como" avaliar são questões de poder que implicam a formação da identidade e da subjetividade dos educandos.

A metodologia que favorece a realização dos objetivos propostos segue o caminho que a aproxima de uma arqueologia em moldes foucaultianos (Foucault, 1997). A idéia é identificar os enunciados e as regras ou leis a que obedecem, bem como descrever sistematicamente os enunciados e as diferenças entre eles, distinguindo suas densidades e caracterizando a dispersão acaso existente. As análises, por sua vez, se apresentam beneficiadas pelo recente estudo de Boniol e Vial (2001), no qual demonstram a continuidade de abordagens avaliativas, mesmo das mais antigas, no campo educacional.

A relevância que este esforço pode adquirir deriva do interesse de contribuir para a reflexão de todos que estão interessados na melhoria da qualidade do ensino público, sobretudo daqueles que são diretamente responsáveis pela elaboração de políticas educacionais. 


\section{UNIDADES DO DISCURSO}

Na literatura especializada o discurso da avaliação formativa é utilizado desde meados do século passado, possivelmente datando de 1967. A partir desta época tem sido recorrente nos limites do estruturalismo, tecnicismo e do sistemismo. Scriven, segundo Boniol e Vial (2001), o teria enunciado pela primeira vez para designar a avaliação contínua, interna, cujo objetivo é transmitir ao aluno informações de retorno que pode utilizar para otimizar estratégias de aprendizagem.

Atualmente são encontrados diversos enunciados situados em diferentes domínios.

\section{Avaliação formativa e estruturalismo}

Nos domínios do estruturalismo, pelo menos três enunciados podem ser identificados: a) a serviço da reprodução social; b) da tomada de decisão; e c) da atualização dos dispositivos pedagógicos.

Em conformidade com o enunciado " $a$ " a avaliação contribui como mecanismo de reprodução social criando diferentes níveis de discriminação. Na perspectiva de Bourdieu e Passeron (1975) a instituição escolar reproduz as desigualdades sociais e seus professores e alunos obedecem a regras constantemente atualizadas por serem elementos invariantes da estrutura de reprodução da escola. Para Perrenoud (1999) a avaliação é codificada pela instituição escolar tendo importante peso nas decisões de sucesso ou fracasso escolar. Gilly (citado por De Ketelle, 1986), em tese, admite que a avaliação traduz e serve à ideologia dominante à qual pertence o professor. Entre estes e outros autores há praticamente um acordo assegurando que, na ausência de consciência da importância da avaliação na cadeia de reprodução, o processo avaliativo, mesmo sendo formativo, se presta para confirmar as características socioculturais dos alunos, reprovando e excluindo aqueles que não reproduzem o arbitrário cultural dos grupos ou classe dominante.

A serviço da tomada de decisão, conforme o enunciado " $b$ ", os procedimentos avaliativos obedecem a uma lógica diferente, visando ter gerência sobre as estruturas de ensino e aprendizagem. Boniol e Vial (2001) em relação a este enunciado nos informam que os procedimentos de coleta de informações permitem examinar o grau de adequação entre as informações obtidas e os critérios pertinentes aos objetivos iniciais do programa de formação, ocasionando freqüentes ajustes de orientação e reorientação dos processos de ensino, aprendizagem e avaliação. A 
avaliação, nesse caso, segue várias orientações, com o intuito de ser mais útil. As orientações pedagógicas privilegiam o realce da relação avaliação tomada de decisão, com escolhas freqüentes, rápidas e menos arbitrárias, com base em dados relevantes para a tomada de decisão; os planejamentos, desenvolvimento de planos e técnicas de ação; os processos contínuos e articulados com outras dimensões que acompanham a ação de formação; e, por fim, a tendência de subordinar a avaliação à ação de formação para marcar que esta é que determina os tipos de avaliação.

Segundo Boniol e Vial (2001), Scriven destaca dois tipos de avaliação em meio às orientações pedagógicas existentes, os quais correspondem a uma avaliação somativa por ocorrer ao final do processo e ser levada a efeito por uma equipe externa que aprecia o conjunto das mudanças ocorridas em uma ação de formação; e a uma avaliação formativa por se basear no processo de ensino e aprendizagem, e consistir de uma avaliação global ou setorial das mudanças em uma ação de formação com relação aos seus responsáveis, de modo a ser bem sucedida. A última é interna e é realizada pelos próprios professores.

Para os autores citados, a distinção de Scriven é rica, com uma originalidade que provém do status atribuído à avaliação baseada no processo. Entretanto, em termos dos discursos estruturalistas, importa considerar, nesta distinção, os vínculos regulares de transformações no que deveria ser a estrutura. O processo, tal como utilizado, é o desenvolvimento no tempo. Os tratamentos que a estrutura impõe aos elementos invariantes são os procedimentos.

Atualmente outros enunciados de avaliação formativa têm penetrado no meio educacional brasileiro, veiculado por meio dos estudos de Afonso (2000), Hadji (2001) e Perrenoud (1999, 1999a, 2000).

Afonso (2000) tem enunciado a avaliação formativa como uma "forma de avaliação pedagógica mais congruente com o princípio da comunidade e com o pilar da emancipação", o que em sua opinião é eficaz antídoto às modalidades de avaliação que dão suporte às políticas neoliberais. Adverte, porém, que a avaliação formativa somente ocorre quando o professor:

"Pretende identificar problemas sentidos pelos seus alunos, [e], em vez de constatar a existência de dificuldades, pretende entendê-las e enfrentá-las, [procura] recorrer o mais possivel a diferentes estratégias de análise e registro do que se está a passar na sala de aula." (p. 38)

O domínio de formação, aprendizagem e avaliação no qual se inscreve a noção de avaliação formativa de Afonso (2000) é estruturalista e ainda pode ser considerada como um "dispositivo pedagógico adequado à 
concretização de uma efetiva igualdade de oportunidades de sucesso na escola básica". Seu modo de enunciá-la, no entanto, aproxima-se do enunciado "c", o da atualização dos dispositivos pedagógicos, no qual a avaliação formativa é tida como instrumento eficaz para viabilizar a ação do professor como agente de democratização.

Segundo Boniol e Vial (2001), as preocupações subjacentes em enunciados similares aos de Afonso (2000) estão voltadas para as estruturas, com a atualização de situações e das condições, conforme o modelo avaliacional como garantia de sucesso. Tais enunciados supõem que a avaliação seja negociada, cabendo ao professor explicitar ou clarificar seus critérios, "sob pena de esta modalidade de avaliação funcionar como pedagogia invisível em prejuízo dos alunos dos grupos ou classes sociais mais vulneráveis". Operacionalmente consideram as lógicas da disciplina e dos alunos, ao permitir que o professor organize no tempo os conteúdos, traduza-os em objetivos pedagógicos e em ações a serem desenvolvidas; e ao corresponder à organização temporal das ações dos alunos conforme suas capacidades de entender e organizar as operações, e de resolvê-las. Boniol e Vial (2001) dizem que isto ocorre porque o objetivo é organizar a situação pedagógica do ponto de vista das condições de realização das tarefas propostas e do ponto de vista da concepção dos dispositivos que gera.

A avaliação formativa para Afonso (2000) é também um dispositivo pedagógico de "acesso ao sucesso", considerando-se os aspectos de orientação pedagógica, auto-avaliação e autocorreção. O professor, em contrapartida, tem garantia das aprendizagens, transferência de saberes, organização das estruturas de formação e de funcionamento. Nestes casos e do ponto de vista do autocontrole, a avaliação formativa, segundo Boniol e Vial (2001), "favorece a análise da tarefa pelo aluno, aumenta o controle que exerce sobre seu próprio processo de aprendizagem, maior valorização da auto-imagem dos alunos e modificação da representação dos colegas".

Hadji (2001), por sua vez, em uma trajetória próxima à de Afonso (2000), mas em uma perspectiva mais técnica e não menos engajada também tem enunciado a avaliação formativa. Ele dá a conhecê-la promissoramente em todos os professores que compreendem poder se colocar a serviço de uma relação de ajuda: "É a intenção dominante do avaliador que torna a avaliação formativa (...), é a vontade de ajudar que, em última análise, instala a atividade avaliativa em um registro formativo". Em suas palavras, a avaliação formativa é promissora, como prática colocada a serviço das aprendizagens.

Hadji (2001) correlaciona a avaliação formativa às atividades em favor das aprendizagens e aos processos de monitoramento, com vistas a 
garantir a eficiência da ação formadora e da aprendizagem, e impedir desperdícios. A lógica mais subjacente nesta correlação é a de minimizar os meios e de maximizar os benefícios, ainda que sejam importantes a variabilidade e a riqueza da ação pedagógica. Admite, entretanto, que a avaliação formativa ainda será somente promissora enquanto perdurarem alguns obstáculos à sua adoção, uma vez que "as representações inibidoras", a "pobreza atual dos saberes necessários" e a "preguiça, ou medo, dos professores, que não ousam imaginar remediações", são os principais obstáculos à sua concretização (p.24).

São grandes, como se pode notar, as aproximações entre os enunciados de Hadji (2001) e Afonso (2000): ambos se inscrevem em um domínio estruturalista que preza o exame dos dispositivos funcionais com centralidade nos dispositivos de ajuda, e estão muito próximos ao enunciado da atualização dos dispositivos pedagógicos. Para os dois autores a avaliação formativa pressupõe o arranjo da situação pedagógica do ponto de vista das condições de realização das tarefas propostas, considerando a lógica da disciplina (conteúdos, objetivos...) e a dos alunos (exercícios, problemas...).

Perrenoud $(1999,1999$ a, 2000) é outro autor a enunciar a avaliação formativa, talvez o mais influente nos dias correntes. Como Afonso (2000) e Hadji (2001) também a insere em domínios da avaliação estruturalista, porém situa-se próximo ao enunciado dos sociólogos interessados em dar visibilidade aos mecanismos de reprodução social presentes no papel desempenhado pelas escolas. Para Perrenoud tal avaliação é condição para reconstituir os procedimentos em um sentido formativo que sejam identificados, não só os invariantes da estrutura escolar, mas também as regras e a doutrina não-escrita da organização escolar, a diversidade de concepções, e as práticas dos professores.

Seu enunciado de avaliação formativa coloca-a como contribuição para "a regulação das aprendizagens" e, ao mesmo tempo, como elemento importante para a existência de escolas eficientes, não emperradas pela rigidez institucional que ainda obedecem a lógicas de seleção e exclusão, e por sua compatibilidade com "uma escola mais eficaz, que prepare melhor para a vida sem, por isso, custar mais caro" (1999a). Apresenta-a também como estratégia para superar a avaliação tradicional ou normativa, lutar contra o fracasso escolar e a lógica da "medida obsessiva da excelência", todavia condiciona que a regulação da ação pedagógica seja deslocada para o nível das aprendizagens, seja individualizada e não fique confinada às escolas experimentais. Perrenoud acredita que isto deve ocorrer quando: 
"Toda prática de avaliação contínua [pretende] contribuir para melhorar as aprendizagens em curso, qualquer que seja o quadro e qualquer que seja a extensão concreta da diferenciação do ensino." (1999)

A avaliação formativa em sua perspectiva pressupõe que ensinar seja orientar, isto é, regular o processo de aprendizagem dos alunos no sentido do domínio de um currículo definido. A regulação visa atingir os objetivos propostos, devendo ocorrer conforme a modulação dos ritmos e níveis das informações, trabalhos práticos, seminários, testes, exames bimestrais ou trimestrais. Diferentemente de Afonso (2000) e Hadji (2001) extrapola, no entanto, os domínios avaliacionais do estruturalismo e do enunciado da atualização dos dispositivos pedagógicos, tendendo a aproximar-se dos marcos limítrofes do sistemismo, particularmente ao priorizar a regulação dos processos de aprendizagem e as retroações sobre as aprendizagens. Nessa aproximação admite que as regulações somente são formativas quando incidem sobre os processos de aprendizagem, os funcionamentos intelectuais dos alunos e as condições de aprendizagem: motivação, participação, aplicação no trabalho, ambiente, estruturação da tarefa e da situação didática.

Perrenoud (1999), aliás, vai além de uma simples aproximação aos marcos do sistemismo; na verdade ele opta pela perspectiva sistêmica mesmo sabendo que isso significa distanciar-se da "cultura comum de todos os pesquisadores e de todos os inovadores" (p. 159). Argumenta que vale a pena: "não se faz avaliação formativa sozinho", é preciso vencer o individualismo dos professores, é preciso exercer controle cerrado sobre a pedagogia dos professores, a avaliação formativa "poderia dar à administração escolar mais controle sobre a qualidade e a conformidade do ensino de uns e de outros", o ideal é caminhar para uma prática refletida e uma profissionalização (p. 152-153).

Afonso e Hadji, não obstante as aproximações existentes entre ambos, a rigor não postulam o enunciado correspondente à atualização dos dispositivos pedagógicos, pois suas ênfases deslocam-se do estudo de tais dispositivos. Somente a consideração das lógicas dos alunos e das disciplinas, assim como o envolvimento dos alunos na negociação das regras, tarefas e condições de realização das tarefas, são insuficientes para caracterizar a atualização dos dispositivos.

Boniol e Vial (2001) nos informam que os dispositivos pedagógicos neste enunciado resultam de concepções psicopedagógicas capazes de orientar as ações e a aquisição de conhecimentos. Em termos avaliativos, devem ainda permitir o aumento do autocontrole dos alunos, por meio do desenvolvimento das capacidades de auto-avaliação e autocorreção. Afora o explícito objetivo de sucesso, os dispositivos de avaliação visam situar os 56 
alunos como sujeitos autovalorizados em seus próprios processos de aprendizagem, com controle das suas aprendizagens e melhor representação dos demais integrantes do processo de ensinoaprendizagem.

As críticas atuais ao enunciado relativo aos dispositivos pedagógicos consideram o envolvimento dos alunos nas negociações como insuficiente, porquanto apenas desempenham um papel na mecânica funcional de atualização dos dispositivos. A racionalização negociada tende a secundarizar, ou mesmo "esconder", os sujeitos individuais. Boniol e Vial (2001) chegam a afirmar que a ordem do singular é rejeitada em favor da ordem do coletivo; não há práxis. O que predomina é a negação do sujeito, a perda da singularidade da pessoa. Também o papel do professor merece críticas quando supervaloriza a instrumentação e imprime ao processo uma racionalidade instrumental. Os professores são os reguladores dos processos de ensino, aprendizagem e avaliação, sob o efeito de uma vontade administrativa. A avaliação formativa, nestes termos, não ultrapassa os limites dos processos de aquisição de normas.

\section{Avaliação formativa e as retomadas sistêmicas}

Fora dos domínios do estruturalismo, outros enunciados também são encontrados, em particular, nos limites da ultrapassagem da estrutura dinâmica e do sistema simples do tecnicismo ressignificado em termos cibernéticos. Aí estão as retomadas sistêmicas possíveis de serem apreendidas por meio dos enunciados da avaliação das tarefas, da avaliação formativa e do sistema de regulações. A noção de sistema, no caso, configura "uma organização feita por meio do jogo das regulações e das auto-regulações"; a noção de processo, por sua vez, é entendida como a energia investida na ação, com o objetivo de enriquecer a reflexão sobre os produtos e procedimentos.

Segundo Boniol e Vial (2001), em enunciados relativos às retomadas ou retroações sistêmicas, as regulações pretendem ser antecipadoras, de modo a levar o aluno a melhorar seus procedimentos e obter sucesso. Cabe ao professor criar e organizar as condições para que a auto-regulação discente seja eficaz. O professor, no entanto, deixa de ser o único sujeito na organização do sistema, gestão e utilização de algum dispositivo pedagógico; outros sujeitos adquirem lugares importantes, considerando-se a globalidade do sistema: diretor, orientador, equipe pedagógica e grupos de alunos. O sistema de regulação, nestes enunciados, pretende melhorar a eficiência do sistema pedagógico e, por conseguinte, da aprendizagem, 
percebendo e reconhecendo os acertos e erros, reajustando e retificando as ações. É nítida a intenção de imprimir uma gestão racional à aprendizagem, com etapas definidas e sucessivas de aquisição de domínios (competências e habilidades) que, implícita e explicitamente, visa regular, do exterior e do interior, a caminhada do aluno no decorrer da ação.

Nos domínios das retomadas sistêmicas, que compreende a avaliação das tarefas, tem-se indagado acerca dos procedimentos indispensáveis à realização das tarefas ou das situações de resolução de problemas, visto que avaliar implica construir referenciais para os atores envolvidos nas situações de modo a entenderem o que lhes é proposto. Os professores se fixam, tecnicamente, nos procedimentos de realização das tarefas, ainda que isto signifique perda do essencial, em particular quando se restringem às competências, habilidades e operações. Segundo Boniol e Vial (2001), a noção de avaliação formativa como retomada sistêmica aproxima-se da psicologia do trabalho em termos de comportamento, e a racionalização tecnicista do processo de aprendizagem muito tem a ver com a racionalização que ocorre no processo de produção das fábricas.

Nos domínios do sistemismo, a avaliação formativa, segundo esses autores, leva os alunos a se apropriarem dos dispositivos de avaliação e a dominarem as operações de antecipação e planejamento. A prioridade formativa é a metacognição a partir dos critérios das tarefas com vistas aos produtos esperados. A avaliação formativa é a retomada prioritária, na ordem de importância é a que é manipulada pelo discente. O professor, continuamente, tende a observar a situação de auto-regulação. A ação avaliativa, porém, ocorre a partir do aluno: como pensa o trabalho enquanto é feito, e depois de feito. Positivamente o critério deixa de ser uma norma de conservação, é uma ferramenta a ser melhorada, e a regulação, ao contrário das demais, passa a ser sinônimo de melhoria, de superação. O projeto pedagógico, ao seu tempo, é tido como um projeto social de superação e deve corresponder às expectativas.

$\mathrm{O}$ enunciado relativo à avaliação como sistema de regulações, por fim, tem como objeto central o processo de formação. Nele, a lógica de formação é a da qualidade, e se interessa pouco pelos procedimentos. $\mathrm{O}$ aluno não é o objeto a ser transformado, como afirmam Boniol e Vial (2001): é um sujeito que deve aprender a se auto-regular prioritariamente. Ao professor apenas cabe prestar-lhe o auxilio necessário, já que a principal função docente é promover a regulação do Outro para atingir o sucesso. 


\section{Avaliação formativa e tecnicismo}

Nos domínios do tecnicismo, dois enunciados de avaliação também se destacam: as retroações sistêmicas e a avaliação para a recuperação. Segundo Boniol e Vial (2001), ambos são perpassados pelo sentido da cibernética, seja em seu sentido grego: "arte de governar os homens", seja no sentido atual da tecnologia: "arte de fabricar máquinas auto-referenciais programadas". A aplicação de leis técnicas e de formas de controle, independentemente do benefício de tais ações, no campo das práticas sociais, é a sua principal característica.

O tecnicismo presente no enunciado das retroações sistêmicas faz com que o professor leve os alunos a atingir os objetivos propostos, por meio de uma avaliação formativa que regule os percursos, e garanta, de modo articulado, as características dos alunos e as do sistema de formação. Todo o percurso é controlado, desde a entrada - passagem - até a saída, por meio de uma avaliação formativa, pontual, contínua, individualizada e interativa. As regulações subjacentes se destinam, do interior do sistema, à recuperação ou reavaliação dos alunos, ou a evitar recuperações ao final do percurso de aprendizagem. A finalidade é garantir a adequada ação formativa, de modo que o maior número de alunos domine os objetivos propostos. Todas as intervenções docentes são organizadas para garantirlhes o sucesso.

Como tecnologia da pedagogia do sucesso, as retroações sistêmicas, epistemologicamente apresentam-se influenciadas pela "teoria dos objetivos" e pela "pedagogia dos domínios", na linha desenvolvida por Bloom e outros (1972). De um ponto de vista crítico, correspondem a uma adaptação técnica da ação pedagógica aos progressos e problemas de aprendizagem dos alunos, sendo mais uma tecnologia de controle que uma avaliação. De outra perspectiva, são apassivadoras dos alunos, pois os submetem a-criticamente ao referencial dos professores e os adaptam aos seus conteúdos. $\mathrm{O}$ fato de somente o avaliador ter autoridade, está sempre dissimulado na finalidade do programa - ter sucesso; ainda que isto coloque os alunos na condição de coisa avaliada, como reificação da conformidade.

Muitos críticos, entre os quais Boniol e Vial (2001) e os autores que citam, vêem nesta avaliação formativa uma regulação cibernética, limitada, com capacidade de falsificar resultados, principalmente ao perder a dimensão contextual e móvel. Os professores que a praticam também são criticados como idealizadores de uma "máquina de transformar" e de programar os percalços e caminhos que os alunos devem enfrentar e percorrer para superá-los. 
O segundo enunciado, igualmente tecnicista, corresponde à avaliação para a recuperação, que se desenvolve reabilitando o erro como fonte de aprendizagem. Em seus limites os resultados, mais que as intenções ou as razões, é que são importantes. A quantidade de resultados tidos como errados, determina o funcionamento de retomada suplementar de formação, como recuperação. Ao professor cabe ajustar os dispositivos pedagógicos (orientações, competências e habilidades, principalmente) para que os alunos superem os resultados negativos, dominem e reproduzam com sucesso os procedimentos.

As críticas a este enunciado expõem a avaliação técnica, cibernética, que visa ao controle e leva os alunos a estados de conformidade, coerência e aceitação passiva do instituído. O professor é um controller que traça os destinos dos alunos, como autêntico senhor dos dispositivos de ensino, aprendizagem e avaliação. É menos o que educa. Sua preocupação com a aprendizagem claramente se confunde com a regulação dos dispositivos, no sentido de suprimir a ignorância dos alunos. Outras críticas recaem ainda sobre a transformação dos objetivos e trabalhos escolares em produtos, assim como também sobre a transformação do processo que se traduz em uma produção quantitativa de resultados. O professor, entretanto, impede as transformações dos saberes, levando os alunos apenas a interiorizá-los para serem integralmente restituídos. Os referenciais de partida permanecem fixos, conservados por meio das regulações. O conservadorismo e o empirismo característicos, além de conformar os alunos, levam-nos a preferir os procedimentos técnicos e práticos, por serem mais visíveis e palpáveis. As dissertações e os temas das Ciências Humanas, por exemplo, tendem a ser desprezados, pois as preferências recaem sobre as ciências tidas como exatas.

\section{A DESCONTINUIDADE DO DISCURSO}

O discurso da avaliação formativa apresenta, como é notável, o caráter de não ser o mesmo em qualquer acepção. Caracteriza-o uma visível dispersão. A análise dos enunciados, contudo, favorece a visão da regulação como domínio comum e contínuo no discurso da avaliação formativa. Todavia, é preciso muita cautela para afirmar que esta visão seja a única a indicar-lhe singularidade e continuidade.

Boniol e Vial (2001) parecem enfrentar o mesmo problema colocado pela descontinuidade presente nestes enunciados. Eles consideram que a avaliação formativa está na moda, que, genericamente e de forma ampla, serve a todo processo de regulação e que tem tido denominações e 
orientações diversas. Já a encontraram denominada como "avaliação ajuste" - centrada nos alunos; "avaliação regulação" - centrada no objetivo; "avaliação negociação" - centrada nas negociações entre professores/alunos. Destarte, diante do problema de descontinuidade, estes autores expõem duas condições para a avaliação ser de fato formativa: 1) que seja um procedimento e um dispositivo de regulação; e 2) que as regulações refiram-se às operações discentes. Não obstante, ainda assim consideram a questão não resolvida. Dois outros problemas se preservam evidentes: como funciona a regulação? Como pode ser definida a participação do aluno para que não se confunda com os resultados pelos quais se interessa a avaliação controle?

No campo de pesquisa que temos abrangido, é igualmente difícil encontrar respostas para os problemas apontados. Observações feitas revelam que algumas práticas, mesmo sendo adjetivadas de formativas, resultam de intuições imediatas dos professores e quase sempre estão desprovidas de visão, enfoque e objetivos que, efetivamente, devem caracterizar uma prática formativa. $\mathrm{Na}$ rede de escolas públicas da cidade do Rio de Janeiro diversas práticas tidas como formativas se ressentem dos apoios necessários, a começar pelas crônicas ausências do poder público e da precariedade em que se encontra o sistema de ensino público municipal.

Uma coisa, entretanto, parece ser clara quando se observa empiricamente uma prática avaliativa qualquer: obviamente nem sempre é uma avaliação formativa, mesmo reconhecendo, como Perrenoud (1999), a presença de aspectos formativos em toda avaliação contínua. Contudo, de um ponto de vista foucaultiano, e considerando-se as práticas e os enunciados do discurso da avaliação formativa, parece ser claro que não se pode falar de qualquer coisa em qualquer época. É importante que as relações entre os enunciados desenhem a trama da avaliação formativa e definam sua constituição interna. Não basta que uma prática avaliativa seja denominada de formativa. A simples denominação não a faz formativa.

Também os autores dos enunciados considerados anteriormente, em suas posições relativas à mesma questão, deixam de avalizar qualquer prática como avaliação formativa. Para Afonso (2000), o campo da avaliação formativa transcende os testes referidos a critérios, ainda que se lhes possa recorrer. A avaliação formativa, em sua perspectiva, não se realiza "mediante provas ou testes deliberadamente construídos, com preocupações técnicas e metodológicas, obedecendo aos requisitos normais, nomeadamente em termos de garantia de validade e fidedignidade". Também não se realiza para controle sistemático dos alunos, pois pode se revelar um importante instrumento, mais opressivo ainda que a avaliação tradicional. A condição para existir uma avaliação formativa como 
dispositivo pedagógico, em sua opinião, é a "concretização de uma efetiva igualdade de oportunidade de sucesso na escola básica".

Hadji (2001), por seu turno, condiciona a formatividade da avaliação ao sentido do projeto no qual se inscreve. Somente ao integrar uma ação de formação ou um registro formativo, em uma relação de ajuda, é que admite a avaliação formativa. Neste sentido, é um modelo de regulação com vistas a atingir os objetivos, não a seguir o caminho. "Não é um modelo científico, nem um modelo de ação diretamente operatório". A avaliação formativa correlaciona atividade de avaliação e atividade pedagógica, sem ser um modelo acabado ou pronto. Mais formalmente explicita quatro condições essenciais para sua ocorrência: a) ter sempre o objetivo de esclarecer os atores do processo; b) recusar limitar-se a uma única maneira de agir, a práticas estereotipadas; c) tornar os dispositivos transparentes; d) desconfiar dos entusiasmos e dos abusos de poder.

Perrenoud (1999), ao seu tempo, diferentemente dos demais, é mais condescendente ao admitir uma parcela de avaliação formativa em qualquer pedagogia, frontal ou tradicional, principalmente na escola de ensino fundamental. Condiciona, todavia, sua prática à regulação de toda ação educativa de certa duração, por meio de intervenções individualizadas, à incidência direta sobre os processos de aprendizagem, funcionamentos intelectuais, e condições de aprendizagem. Os professores que verdadeiramente a utilizam, em sua perspectiva, têm tempo e continuidade, recorrem aos trabalhos sobre o erro e aos progressos da didática das disciplinas, limitam o efetivo em sala de aula, e ouvem os alunos, tal qual um psicólogo piagetiano, diagnosticando e definindo-lhes ótimas intervenções.

Parece, então, ser consensual que qualquer prática avaliativa não se traduz, por si mesma, em avaliação formativa; sua realização impõe níveis de consciência pedagógica aos professores e capacidade de regulação, indispensáveis à ação de formação. A simples intenção de levar os alunos a obter sucesso por meio de algum teste, prova ou exercício aplicado com o intuito de melhorar os resultados, ou a discussão dos objetivos de alguma tarefa ou exercício de avaliação com os alunos, ou ainda o acompanhamento de perto os modos de trabalhar, tudo isto pode ser insuficiente para configurar uma avaliação formativa. Em nossa opinião, tão somente, significa pretender atenuar as tensões típicas da sala de aula, ou, o pior, ser uma estratégia comum para diminuir o número de alunos com conceitos insuficientes.

Em pesquisa realizada noutra oportunidade (Gama, 2002), pude observar que muitos professores têm utilizado vários instrumentos informais de avaliação e critérios com base na freqüência às aulas, interesse, 
realização das tarefas propostas e cumprimento de prazos. Alguns se consideram formativos por agirem assim. Outros alegam outras razões, mas nenhum visa regular, por exemplo, a aprendizagem dos alunos em conformidade a determinado programa de ensino. Por absurdo que seja, há, por exemplo, verbalizações relacionadas à necessidade de diminuir a sobrecarga de trabalho pelo fato de se ter mais de uma jornada e outras opções de lazer. Um professor chega a verbalizar isto deste modo:

“Utilizo-me de vários instrumentos de avaliação: material atualizado, freqüência, interesse, participação, cumprimento de tarefas e prova por conteúdos. Sendo que esta última era utilizada por mim antes de ter três empregos."

\section{CONSIDERAÇÕES FINAIS}

A arqueologia do discurso da avaliação formativa, aqui ensaiada, dá visibilidade às unidades enunciadas, mas ao invés de mostrar a existência de um discurso com o caráter de ser o mesmo em qualquer acepção, revela a dispersão existente e as possíveis opções de filiações metodológicas. A utilização da avaliação formativa então determina cautela e aprofundadas reflexões antes de sua utilização.

Talvez a reflexão primeira deva estar relacionada aos interesses subjacentes aos enunciados da avaliação formativa, a começar pela idéia de sucesso, aliás muito saliente em todos eles. Para Perrenoud (1999), em particular, esta idéia deve estar articulada à preocupação com a eficácia e com a eficiência da escola, dos processos de ensino e aprendizagem, e tem a ver com a necessidade de inclusão social de todos como fator de sustentação da sociedade democrática e da própria governabilidade do Estado e da sociedade. Afonso (2000), por sua vez, mas em outra linha, justifica sociologicamente a emergência de novas modalidades de avaliação, incluindo a avaliação formativa, a partir da necessidade de maior responsabilização do Estado, das escolas e dos professores com os "clientes" dos sistemas de ensino.

O caráter taumatúrgico da avaliação formativa, por mais que se apresente como "progressista", na verdade, tem um tom conservador e tecnocrático acentuadamente preocupado com a eficácia, a competitividade e a excelência, visando a transformações que se dão, sobretudo em níveis de administração e gestão dos sistemas de ensino. Tal caráter, além de afetar a autonomia dos professores e das escolas, busca redistribuir os poderes de decisão e controle. 
Há, porém, outras reflexões considerando-se que a própria avaliação formativa pouco avança por causa de sua pequena ou nenhuma capacidade de desconfiar, questionar e propor transformações radicais. Ideologicamente, a maior parte dos seus enunciados prossegue desenvolvendo contribuições que servem para a inculcação de crenças explícitas e normas compatíveis com a desejabilidade das estruturas sociais, assim como inclina professores e alunos ao monitoramento e ao controle, à submissão e à obediência, em tempo de redefinição das relações entre os indivíduos e o Estado. O explícito desejo de inclusão social de todos, contudo, sequer assegura o desenvolvimento de hábitos e habilidades próprias das classes dominantes ao longo da escolaridade.

Por fim, se são consideradas as teorias de currículo pós-críticas ${ }^{1}$, os enunciados de avaliação formativa também ficam a dever, particularmente por deixarem de apresentar alternativas ao desenvolvimento destas novas teorias e de por em xeque o poder. Seus enunciados, concretamente, não apontam para transformações. Situam-se longe das propostas educacionais críticas ou progressistas. Preferem propor mudanças ou inovações para a manutenção do status quo. Continuam a preferir a conservação da ordem.

\section{REFERÊNCIAS BIBLIOGRÁFICAS}

AFONSO, A. J. Avaliação Educacional: regulação e emancipação - para uma sociologia das políticas avaliativas contemporâneas. São Paulo: Cortez, 2000.

BLOOM, B. S. et al. Taxionomia de objetivos educacionais. Porto Alegre: Globo, 1972.

BONIOL, J-J ; VIAL, M. Modelos de Avaliação: textos fundamentais. Porto Alegre: Artmed, 2001.

BOURDIEU, P.; PASSERON, J-C. A reprodução: elementos para uma teoria do sistema de ensino. Lisboa: Editorial Vega, 1975.

CUNHA, L. A. C. Educação, Estado e Democracia no Brasil. São Paulo, Niterói e Brasília: Cortez/Eduff/ Flacso, 1995.

1 Entre as teorias curriculares pós-críticas, podem ser incluídas aquelas que abordam o currículo na perspectiva multiculturalista, dos estudos culturais, de gênero, de narrativas étnica e racial, pós-modernista, pós-estruturalista e pós-colonialista. Para maior aprofundamento ver Silva, 2002. 
DE KETELLE, J-M. L'évaluation: approche descriptive ou prescriptive? Bruxelas: De Boeck, 1986.

FOUCAULT, M. Arqueologia do Saber. Rio de Janeiro: Forense, 1997.

GAMA, Z. J. Avaliação na Escola de Ensino Fundamental: continuidade de padrões e tendências. Rio de Janeiro, 2002. Tese (dout.) Universidade Federal do Rio de Janeiro (UFRJ).

HADJI, Ch. A avaliação desmistificada. Porto Alegre: Artmed, 2001.

PERRENOUD, Ph. Avaliação: da excelência à regulação das aprendizagens entre duas lógicas. Porto Alegre: Artes Médicas Sul, 1999.

PERRENOUD, Ph. Construindo competências. Revista Nova Escola, edição n. 135. São Paulo: Abril Cultural, 2000.

PERRENOUD, Ph. Construir as competências desde a escola. Porto Alegre: Artes Médicas Sul, 1999.

SECRETARIA DE ESTADO DE EDUCAÇÃO DO RIO DE JANEIRO. Programa Nova Escola. Rio de Janeiro: Disponível no site: www.see.rj.gov.br/novaescola.htm. Acessado em abril de 2002.

SECRETARIA DE ESTADO DE EDUCAÇÃO DO RIO DE JANEIRO; FUNDAÇÃO CESGRANRIO. Programa Nova Escola: Avaliação do Desempenho Escolar - Análise dos resultados das questões da prova do Ensino Fundamental e Fase III do Supletivo. Rio de Janeiro: SEE-RJ/ Cesgranrio, 2000.

SILVA, T. T. Documentos de Identidade: uma introdução às teorias do currículo. Belo Horizonte: Autêntica, 2002.

Recebido em: janeiro 2004 Aprovado para publicação em: fevereiro 2004 
